\title{
Cellular Differentiation of Non-Transformed Intestinal Epithelial Cells Is Regulated by Lactobacillus rhamnosus and L. casei Strains
}

\author{
J. KOLINSKA ${ }^{1}$, M. ZAKOSTELECKA ${ }^{1}$, Z. ZEMANOVA $^{1}$, V. LISA ${ }^{1}$, J. GOLIAS ${ }^{2}$, \\ H. KOZAKOVA ${ }^{3}$, B. DVORAK ${ }^{4}$
}

${ }^{1}$ Institute of Physiology of the Czech Academy of Sciences, Prague, Czech Republic, ${ }^{2}$ Laboratory of Cellular and Molecular Immunology, Institute of Microbiology of the Czech Academy of Sciences, Prague, Czech Republic, ${ }^{3}$ Laboratory of Gnotobiology, Institute of Microbiology of the Czech Academy of Sciences, Nový Hrádek, Czech Republic, ${ }^{4}$ Department of Pediatrics and the Steele Children's Research Center, The University of Arizona, Tucson, AZ, USA

Received April 3, 2017

Accepted October 9, 2017

On-line January 5, 2018

\section{Summary}

The aim of this study was to characterize an in vitro modulating effect of three commensal Lactobacillus strains on cellular differentiation of non-transformed crypt-like rat small intestinal cell line IEC-18. IEC-18 was grown on extracellular matrix, with or without presence of Lactobacillus strains. Gene expression of IEC-18 bacterial detection system - such as Toll-like receptors TLR-2, TLR-4, signal adapter MyD88, cytoplasmic NOD2 receptor, inflammatory cytokines IL-18, IL-1 $\beta$, chemokine IL-8 and enzyme caspase- 1 - was evaluated using real-time PCR. Expression and localization of TLR-2, TLR-4, IL-18 and caspase- 1 proteins was demonstrated by Western blotting and immunofluorescent staining. Secretion of IL-18 to apical and basolateral surfaces was assayed by ELISA. Our results suggested that L. casei LOCK0919 accelerated differentiation of IEC-18 by stimulating TLR-2, TLR-4, MyD88, IL-18, caspase-1 mRNAs and proteins. L. casei LOCK0919 increased expression and transfer of villin and $\beta$-catenin from cytoplasm to cell membrane. Presence of L. rhamnosus LOCK0900 resulted in detachment of IEC-18 layer from extracellular matrix leading to induction of IL- $1 \beta$, of TLR-2 and IL-8 mRNAs and stimulation of MyD88, caspase- 1 and cytosolic receptor NOD2 mRNAs. L. rhamnosus LOCK0908 was not recognized by TLR-2 or TLR-4 receptors. Lactobacilli-IEC-18 crosstalk enhanced immune and barrier mucosal functions.

\section{Key words}

IEC-18 • Lactobacillus • IL-18 • TLRs • Caspase-1 • Villin • $\beta$-catenin

\section{Corresponding author}

J. Kolínská, Institute of Physiology CAS, Vídeňská 1083, 14220 Prague 4, Czech Republic. E-mail: kolinskasci@gmail.com

\section{Introduction}

The epithelial surface of the small intestine is separated from the intestinal lumen by a single epithelial cell layer constantly migrating along the crypt/villus axis within 3-5 day cycle from the proliferative undifferentiated crypt cells to the fully differentiated polarized columnar enterocytes with apical and basolateral membrane domains. The enterocytes are the most abundant cell type which together with Paneth and goblet cells contribute to mucosal defense and maintenance of barrier integrity (Ismail and Hooper 2005). Intestinal epithelial cells (IEC) provide their own control of proliferation and differentiation of cell functions. Presence of non-differentiated stem cell precursors permits epithelial self-renewal. The actin cytoskeleton plays the major role in cell migration, cell-to-cell adhesion and also in cell proliferation and differentiation (Heath 1996). IEC exist as adherent cells attached to a basement membrane consisting of various extracellular matrix proteins (ECM). The molecular conformation of ECM, such as laminin and collagen, modulate the epithelial cell phenotype (Kedinger 1994). Incubation in vitro of nonmalignant IEC on 
ECM-Matrigel induces changes in IEC phenotype toward full differentiation, such as expression of digestive brushborder enzymes (Sanderson et al. 1996, Kolinska et al. 2008) and regulation of IEC polarity (Jalal et al. 1992). The short life cycle of enterocytes is terminated by physiological apoptosis/shedding after their gradual detachment from ECM proteins.

The IEC monolayer serving as the interface between the host and environment is constantly exposed to bacterial content in the gut lumen. IEC possess receptors for molecules derived from bacterial cell wall. Toll-like transmembrane receptors (TLR) are a key group of pattern recognition receptors; DNA transcription generates their mRNAs that carry the information for protein synthesis. TLR-2 and TLR- 4 mRNAs had been detected in human colon cancer cell lines T84 and HT-29 but proteins were weakly detectable (Stadnyk et al. 2001). However, surface protein expression of TLR-2 of $85 \mathrm{kDa}$ and TLR-4 of $92 \mathrm{kDa}$ was visualized on T84 cells (Cario et al. 2000). Synthesis and insertion of transmembrane receptors to plasma membrane operate according to hypothesis of Blobel et al. (1979); the integral protein destined for the plasma membrane is synthesized on polyribosomes and its signal peptide enables attachment to rough endoplasmic reticulum (ER) and travel from ER to the site of complex glycosylation through the Golgi and trans-Golgi network, the protein then fuses with plasma membrane. Demonstration that TLR-2 and TLR-4 exist on normal human IEC helped explain the capacity of human enterocytes as non-classical immune cells to function as active participants in immune response and physical barrier to bacterial substances (Fusunyan et al. 2001). The second major group of pattern recognition receptors is a nucleotide-binding domain (NOD) family, a group of cytoplasmic proteins that does not contain a transmembrane domain, does not act as membrane receptor (Barnich et al. 2005) and does not contain a signal peptide. The authors assumed that NOD2 interacts with the inner side of the plasma membrane necessary for NOD2 to recognize its bacterial ligand muramyl dipeptide and to activate nuclear factor kappa $\mathrm{B}$ (NF-kB).

Probiotics are living, non-pathogenic microorganisms that colonize the intestine and provide benefit to the host. In this study, we have tested the effect of three probiotic Lactobacillus strains L. rhamnosus LOCK0900, L. rhamnosus LOCK0908 and L. casei LOCK0919 isolated from human fecal samples and known for their anti-allergic ability (Cukrowska et al. 2010, Kozakova et al. 2016). We have used a model of non-transformed undifferentiated small intestinal cell line IEC-18 derived from the rat ileum that undergoes differentiation during cultivation on ECM similarly as IEC-6 line (Kolinska et al. 2008). We intended to characterize the modulating effect of probiotic bacteria on immunological and morphological functions during differentiation. Activation of TLRs by commensal bacteria is essential in maintaining intestinal epithelial homeostasis (Michelsen and Arditi 2007). Thus, gene expression of TLR-2, TLR-4 and internal NOD2 receptor activation at mRNA level have been evaluated. Next we followed MyD88, an adaptor functional molecule critical for TLRs-mediated signaling and transcription of chemokine IL-8. Expected modulation of TLR protein glycosylation by commensal bacteria have been correlated with the degree of cell differentiation. Furthermore, we focused on the effect of Lactobacillus strains on gene expression of inflammatory cytokines, interleukin IL-18 and IL-1 $\beta$, sharing a common maturation mechanism that requires intracellular enzyme caspase-1. Previously, we have shown a correlation between constitutive expression of IL-18 and caspase-1 proteins (Kolinska et al. 2008). Leaderless proteins IL-1 $\beta$ and IL-18 are actively secreted by human monocytes and dendritic cells, respectively, via a pathway of secretion different from the classical ER-Golgi pathway. Instead, secretion operates at the level of both proteolytic processing and extracellular export and may be increased by stress conditions (Rubartelli et al. 1990, Gardella et al. 1999). In this study, we are also characterizing subcellular localization of cytoskeleton binding proteins villin and $\beta$-catenin in course of IEC differentiation and effect of lactobacilli.

\section{Materials and Methods}

\section{Bacterial strains}

L. rhamnosus LOCK0900 (L900) (AleksandrzakPiekarczyk et al. 2013), L. rhamnosus LOCK0908 (L908) (Koryszewska-Baginska et al. 2014) and L. casei LOCK0919 (L919) (Koryszewska-Baginska et al. 2013) were obtained from the Pure Culture Collection of the Technical University of Lodz, Poland (LOCK). Overnight cultures in MRS broth (Oxoid, Basingstoke, UK) were centrifuged, washed in sterile phosphatebuffered saline (PBS) and concentration was adjusted to $10^{9} \mathrm{CFU} / \mathrm{ml}$. Single bacterial strains were inactivated 
with $1 \%$ formaldehyde-PBS for $3 \mathrm{~h}$ at room temperature, washed twice with sterile PBS and stored at $-20{ }^{\circ} \mathrm{C}$. Each bacterial strain was applied to IEC-18 cells at $10^{7} \mathrm{CFU} / \mathrm{ml}$ for $2 \mathrm{~h}$ either separately or in an equal-part mixture (Lac).

\section{IEC-18 cultures}

The non-transformed rat intestinal epithelial cell line IEC-18 derived from ileum was obtained from American Type Culture Collection (ATCC, CRL-1592, Manassas, VA, USA). The stock culture was grown in Dulbecco modified Eagle medium (DMEM) in $95 \%$ air, $5 \% \mathrm{CO}_{2}$ at $37{ }^{\circ} \mathrm{C}$. The medium contained $40 \mu \mathrm{g}$ gentamicin $/ \mathrm{ml}, 2 \mathrm{mM}$ glutamine, $50 \mathrm{ml}$ fetal bovine serum (FBS)/1 and $10 \mathrm{mg}$ insulin/l (Kolinska et al. 2008). Passages 15-27 were used in this study. For real-time PCR and Western blot the cells were plated at a density of $1.6 \times 10^{6} / \mathrm{cm}^{2}$ onto plastic plates (60 $\mathrm{mm}$ in diameter) coated with Matrigel (Engelbreth-Holm-Swarm sarcoma basement membrane, Sigma, St. Louis, MO, USA). For IL-18 bipolar secretion and cell accumulation assay (ELISA, Biosource Internat., Nivelles, Belgium) the cells were seeded on either non-coated or collagen coated $6.5 \mathrm{~mm}, 5 \mu \mathrm{m}$ pore-size Costar Transwell filter inserts (Corning Corporation, Corning, NY, USA) in a two-compartment system. The cultivation medium contained a mixture of five nucleotide monophosphates (10 mg/l each) added on the second day after seeding. On day six the medium was changed to a medium with a lower amount of FBS $(5 \mathrm{ml} / \mathrm{l})$ for $24 \mathrm{~h}$. On day seven formolized bacteria $\left(10^{7} \mathrm{CFU} / \mathrm{ml}\right)$ were added for $2 \mathrm{~h}$ before the harvest. Culture supernatants were collected and stored at $-75^{\circ} \mathrm{C}$. Cells were harvested by gentle trypsinization with $0.25 \%$ trypsin $-0.3 \%$ EDTA, washed with PBS and, after estimating the cell counts, pelleted at $10,000 \mathrm{~g}$. The pellets were homogenized 1) in lysis buffer RLT for RNA isolation or 2) in lysis buffer for Western blot and ELISA (Vallee et al. 2004) containing protease inhibitor cocktail (Sigma) and $1 \mu \mathrm{M}$ each of aprotinin, leupeptin and pepstatin. Cell lysates were centrifuged at $15,000 \mathrm{x} g$ for $10 \mathrm{~min}$ at $4{ }^{\circ} \mathrm{C}$ and the supernatants stored at $-75^{\circ} \mathrm{C}$ after assaying their protein content.

\section{Western blotting}

Supernatants obtained after homogenization of cell pellets in lysis buffer of protein concentration $1.5 \mathrm{mg} / \mathrm{ml}$ were separated on the $5-20 \%$ SDS-PAGE under reducing conditions. Separated proteins were transferred onto nitrocellulose membranes blocked with
Tris-buffered saline with $0.1 \%$ Tween 20 (TBS) (Golias et al. 2013). Blocked membranes were incubated with a primary antibody $(\mathrm{Ab})$ diluted in TBS containing $0.1 \%$ defatted milk (Promil, Nový Bydžov, Czech Republic) for $1 \mathrm{~h}$ at room temperature. Primary Abs: goat anti-IL-18 diluted 1:5,000, goat anti-TLR-2 and goat anti-TLR-4, both diluted 1:500 (Santa Cruz Biotechnology, Santa Cruz, CA, USA); Control recombinant rat IL-18 protein (R\&D Systems, Minneapolis, MN, USA); rabbit anti-caspase-1 (Cell Signaling Technology, Danvers, MA, USA) diluted 1:1,000. The membranes were incubated with peroxidase-conjugated secondary $\mathrm{Ab}$ : donkey anti-goat IgG, goat anti-rabbit IgG (Cell Signaling Technology) diluted 1:5,000 with TBS containing $1 \%$ milk. Signal was detected using the West Femto Maximum Sensitivity Substrate kit (Pierce, Rockford, IL, USA) and exposed onto films (Santa Cruz Biotechnology).

\section{$R N A$ preparation and real-time $P C R$}

Total RNA was isolated from IEC-18 cells using the RNeasy Plus Mini Kit (Qiagen, Santa Clarita, CA, USA) as described in the manufacturer's protocol. RNA concentration was quantified by ultraviolet spectrophotometry at $260 \mathrm{~nm}$, and the purity and integrity were determined using a NanoDrop (Thermo Fisher Scientific, Wilmington, DE, USA). Real-time (RT)-PCR assays were performed to quantify steady-state mRNA levels of IL-8 (CXCL1), caspase-1 (Cas-1), IL-1 $\beta$, IL-18, myeloid differentiation primary response gene 88 (MyD88), nucleotide oligomerization domain (NOD) 2, TLR-2, and TLR-4. cDNA was synthesized from $0.2 \mu \mathrm{g}$ of total RNA. RT-PCR amplification was performed using Primer Express Software ${ }^{\mathrm{TM}}$ (Applied Biosystems, Foster City, CA, USA). Target probe was labeled with fluorescent reporter dye. PreDeveloped TaqMan primers and probes were used for the detection of IL-8, Cas-1, IL-1 $\beta$, IL-18, MyD88, NOD2, TLR-2, and TLR-4. Reporter dye emission was detected by an automated sequence detector combined with ABI Prism 7700 Sequence Detection System ${ }^{\circledR}$ software (Applied Biosystems). RT-PCR quantification was then performed using TaqMan ${ }^{\circledR} 18 \mathrm{~S}$ controls.

\section{Immunofluorescence}

The rat IEC-18 cells were plated on non-coated round coverslips $(30 \mathrm{~mm}$ in diameter) in plastic plates with DMEM-based medium as reported previously. IEC-18 cells were either untreated or treated with $L$. casei 
LOCK0919 $\left(10^{7} \mathrm{CFU} / \mathrm{ml}\right)$ for $2 \mathrm{~h}$ before the end of cultivation. After cultivation for $1,3,5$ or 7 days, the cells were fixed with cold methanol $\left(-25^{\circ} \mathrm{C}\right)$ for a minimum of $1 \mathrm{~h}$ and washed three times with PBS. Non-specific binding of IgG was suppressed with $3 \%$ BSA for $45 \mathrm{~min}$. To increase the permeability of cell membranes, $0.1 \%$ Triton $\mathrm{X}-100$ was added before the overnight incubation with primary antibody $(\mathrm{Ab})$ at $4{ }^{\circ} \mathrm{C}$. Primary Abs: goat anti-villin, goat anti-TLR-2, goat anti-TLR-4 (Santa Cruz Biotechnology, Santa Cruz, CA, USA) all diluted 1:50. Rabbit anti- $\beta$-catenin (Sigma, St. Louis, MO, USA) diluted 1:300. Rabbit anticaspase-1 (Gen Way Biotech, San Diego, CA, USA) ready-to-use. Rabbit anti-IL-18 (Ab Bio Technology, Miami, FL, USA). Secondary antibodies used: donkey anti-goat IgG-FITC (Santa Cruz Biotechnology), and donkey anti-rabbit IgG-TRITC (Jackson Immuno Labs, West Grove, PA, USA), both diluted 1:100 and incubated for $45 \mathrm{~min}$ at room temperature. Mounting medium was Pro Long Anti-fade Gold with 4, 6-diamidino-2phenylindole (DAPI) (Molecular Probes, Eugene, OR, USA) as nuclear marker. The samples were viewed under an Olympus Provis AX 70 microscope equipped with Olympus DP 70.

\section{Statistics}

Statistical analysis of differences between groups of ELISA values was evaluated by one-way analysis of variance (ANOVA). The unpaired Student's t-test was used for relative mRNA levels. Statistical analysis was performed using Graph Pad Prism 5.0
Software (GraphPad Software, Inc., San Diego, CA, USA). All numerical data expressed as mean \pm SEM. $\mathrm{P}<0.05$ was considered to be significant.

\section{Results}

Bipolar IL-18 secretion by IEC-18 cells in response to apical lactobacilli mixture (L. rhamnosus LOCK0900, L. rhamnosus LOCK0908, L. casei LOCK0919)

For IL-18 measurements (ELISA), the IEC-18 cells were seeded either on non-coated or collagen-coated microporous transwell filter inserts in DMEM media in both upper (apical) and lower (basolateral) chambers. The cells were grown for 7 days to achieve their polarity. In collagen-free system (-collagen), the cells grew as less differentiated crypt-like small intestinal epithelial cells. More differentiated villus-like IEC-18 cells were observed on microporous insert coated with collagen (+collagen). The equal-part mixture $\left(10^{7} \mathrm{CFU} / \mathrm{ml}\right.$ each) of three Lactobacillus strains (Lac) was added to the upper chamber of the transwell plates for the last $2 \mathrm{~h}$ of cultivation. Control crypt-like IEC-18 secreted constitutive amounts of IL-18 into both apical and basolateral chambers. Control villus-like IEC-18 secreted higher amounts of IL-18 compared to crypt-like IEC-18 cells. Cultivation of IEC-18 cells with Lac mixture significantly reduced the IL-18 secretion in villus-like epithelial cells (Fig. 1A). Intracellular content of IL-18 in IEC-18 cell layers increased after bacterial challenge, both without/with collagen presence (Fig. 1B).

\section{A}
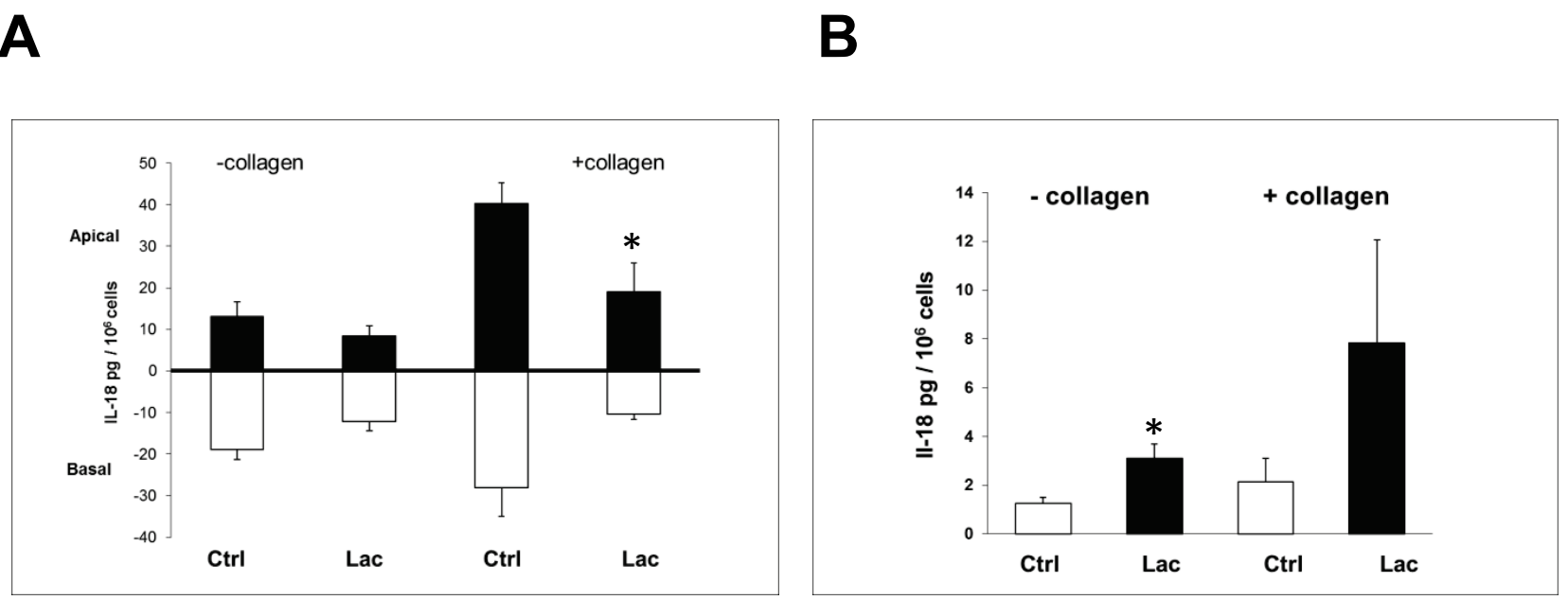

Fig. 1. Interaction between IEC-18 line and ECM is important for cell differentiation. (A) Polarity of IL-18 secretion by IEC- 18 cells. The cells are a source of IL-18 and secrete this cytokine from both their apical and basolateral poles. In response to apical probiotic equalpart mixture $L$. rhamnosus/casei (Lac) the IL-18 secretion is depressed but stays polar. (B) Lac enhances IL-18 protein accumulation in IEC-18 cell layer. In the group with collagen IL-18 production in IEC-18 cells was not significant for higher scatter of data. All numerical data (IL-18 pg/ $10^{6}$ cells assayed by ELISA) are expressed as mean \pm SEM of three groups of wells (4 transwells/group) for each point. $* \mathrm{P}<0.05$, Lac vs. control. 
A

\section{TLR-2}

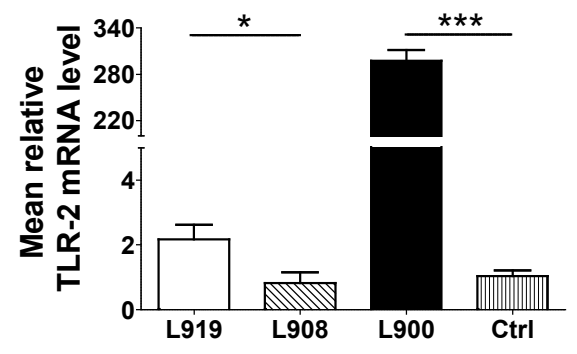

NOD2

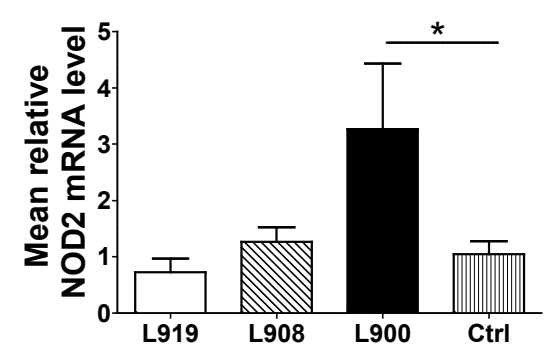

B

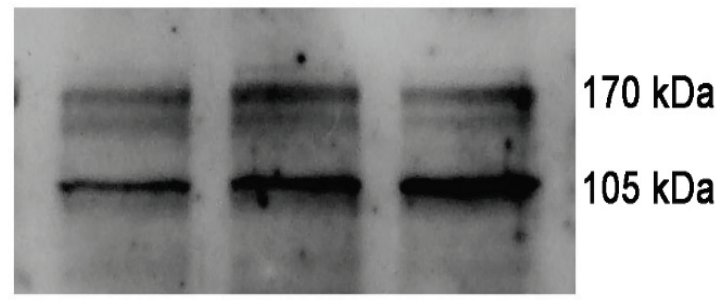

L919

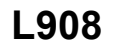

Ctrl
TLR-4

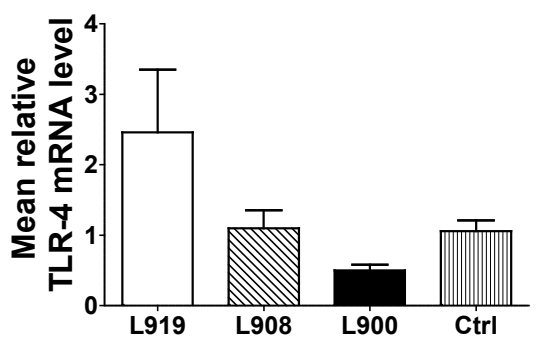

\section{MyD88}

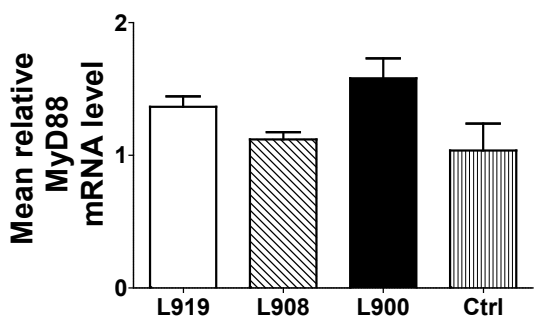

\section{L919 L908 Ctrl}

Fig. 2. Both TLR-2 and TLR-4 mRNA (A) and protein (B) are expressed constitutively in IEC-18 cell lysates after 7-day cultivation on Matrigel in untreated IEC. (A) L. rhamnosus LOCK0900 (L900) (10 7 CFU/ml) exposure for $2 \mathrm{~h}$ stimulated expression of TLR-2 mRNA and NOD2 mRNA. The stimulating effect of L. casei LOCK0919 (L919) on mRNA TLR-2 and insignificant stimulation of mRNA TLR-4 for higher scatter of data were observed. Stimulation of adapter molecule MyD88 mRNA by L. rhamnosus LOCK0900 (L900) and L. casei LOCK0919 (L919) was found insignificant. L. rhamnosus LOCK0908 (L908) exposure to IEC did not differ from control values. (B) Representative Western blot with goat anti TLR-2 and goat anti TLR-4 followed with peroxidase-labeled donkey IgG antibody revealed expression of 100-105 kDa protein bands of TLR-2 and TLR-4 in control as well as under the effect of L. casei LOCKO919 (L919) or L. rhamnosus LOCK0908 (L908). In (A) average mean \pm SEM of three experiments are presented. $* \mathrm{P}<0.05$, L919 vs. control, $* * * P<0.001$, L900 vs. control.

L. rhamnosus LOCK0900, L. rhamnosus LOCK0908 and L. casei LOCK0919 differentially influence $m R N A$ production of TLR-2, TLR-4, NOD2 receptor and adaptor molecule MyD88 important for TLR signal pathways to activate $N F-\kappa B$

Our results in Figure 2 showed strong induction of TLR-2 $(\mathrm{P}<0.001)$ and NOD2 $(\mathrm{P}<0.05)$ relative mRNA levels after cultivation of IEC-18 cells with L. rhamnosus LOCK0900. In contrast to L. rhamnosus LOCK0900 strain, gene expression of NOD2 was not affected by L. casei LOCK0919 treatment. However, significant up-regulation of TLR-2 $(\mathrm{P}<0.05)$ and a mild insignificant stimulation of TLR-4 were observed after cultivation with L. casei LOCK0919 strain. Both probiotic L. rhamnosus LOCK0900 and L. casei LOCK0919 have in common an insignificantly increased expression of mRNA MyD88 functional molecule. No effect of L. rhamnosus LOCK0908 strain either on TLR-2, TLR-4 or NOD2, MyD88 relative mRNA levels was observed. Western blotting using relevant antibodies showed constitutively expressed TLR-2 and TLR-4 proteins in control group of $100-105 \mathrm{kDa}$, which is higher than those shown on human fetal primary small intestinal cell line $85 \mathrm{kDa}$ for TLR-2 and of $92 \mathrm{kDa}$ for TLR-4 (Fusunyan et al. 2001). 
A
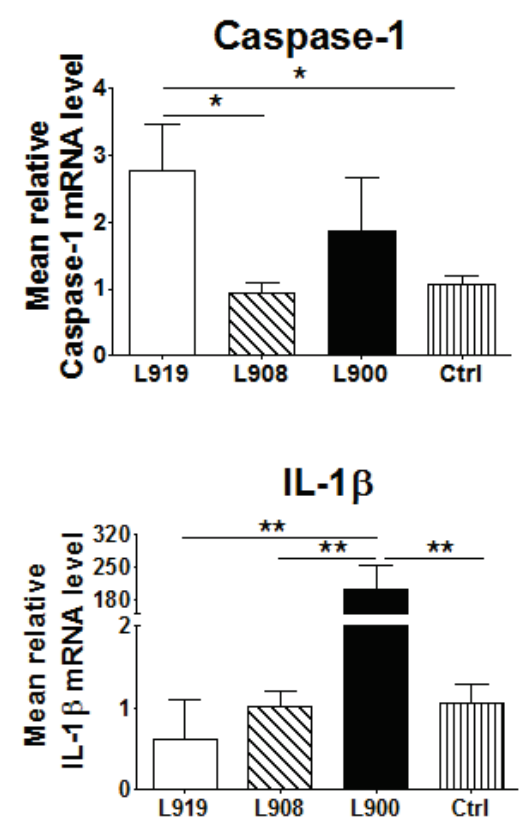

B

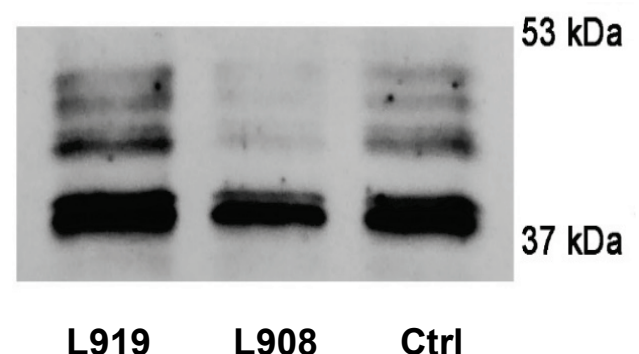

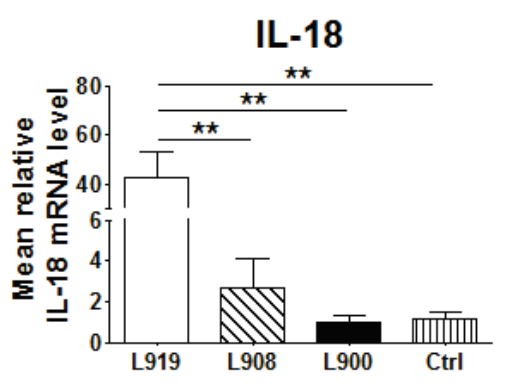

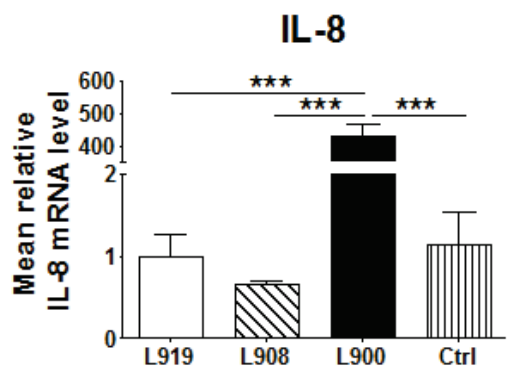

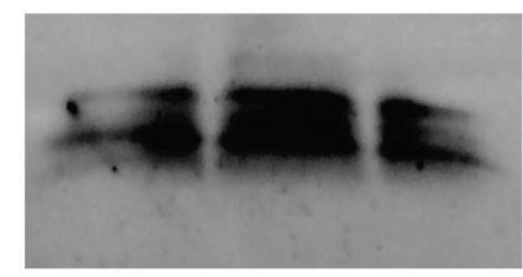

L919

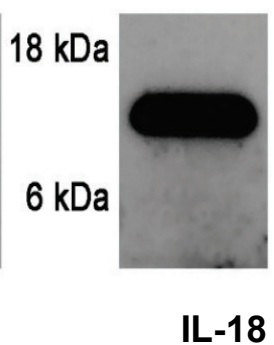

Fig. 3. Caspase-1, IL-18, IL-1 $\beta$ and IL-8 mRNAs expression in IEC-18 cells is differently affected by L. rhamnosus LOCK0900 (L900), L. rhamnosus LOCK0908 (L908) and L. casei LOCK09019 (L919) strains. (A) Mean relative caspase-1 mRNA level and mean relative IL-18 mRNA level are stimulated in the presence of L. casei LOCK0919 (L919) vs. control, $* \mathrm{P}<0.05$ and $* * \mathrm{P}<0.01$, respectively. On the other hand, strain L. rhamnosus LOCK0900 (L900) induced mean relative mRNA levels of IL-1 $\beta$ and IL-8. (B) Western blot analysis showed that cultured IEC-18 cells contain active mature caspase-1 (six protein bands between $37-53 \mathrm{kDa}$ ) in both control and that elevated by L. casei LOCK0919 (L919). Western blot showed three bands of IL-18 among 6-18 kDa correlated with the position of recombinant rat IL-18. Average mean \pm SEM of three experiments are presented. $* P<0.05$, L919 vs. control, $* * P<0.01, L 919$ and L900 vs. control, ***P<0.001, L900 vs. control.

Effect of L. casei LOCK0919, L. rhamnosus LOCK0900 and L. rhamnosus LOCK0908 on the expression of $m R N A$ of the enzyme caspase-1, cytokines $I L-1 \beta, I L-18$ and $I L-8$ in IEC-18 cells

Caspase-1 is a cysteine protease which cleaves inflammatory cytokines pro-IL-18 and pro-IL-1 $\beta$ into their active mature forms. Our results showed that caspase-1 and IL-18 mRNAs were significantly increased after cultivation of IEC-18 cells with $L$. casei LOCK0919 strain (Fig. 3A). In contrast to L. casei LOCK0919, gene expression of caspase-1 was not significantly stimulated and gene expression of IL-18 was not affected after cultivation with L.rhamnosus LOCK0900 strain.
However, significant up-regulation of IL-1 $\beta$ mRNA and IL-8 mRNA appeared after cultivation with $L$. rhamnosus LOCK0900 strain. IL-8 mRNA is a transcription product of TLR-2 activation by bacteria. No effect of L. rhamnosus LOCK0908 strain on studied cytokines was observed. Western blotting (Fig. 3B) using rabbit anticaspase-1 antibody showed six mature active caspase-1 protein forms between $37-53 \mathrm{kDa}$ in control group and in the $L$. casei LOCK0919 treated IEC-18 cells. The three bands in the range of 6-18 kDa of IL-18 obtained after reaction with rabbit antibody to IL-18 may represent pro-IL-18 and also mature IL-18 protein forms correlated with the location of recombinant rat IL-18. 
A

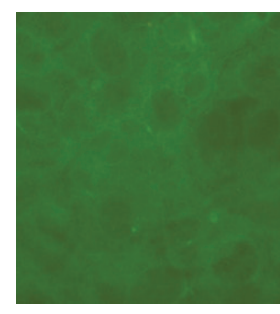

E

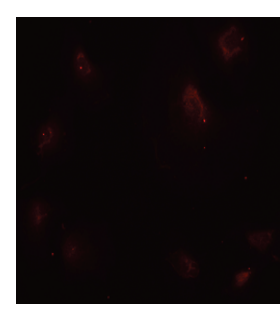

B

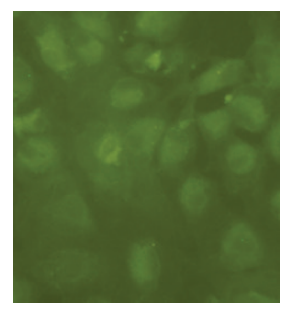

$\mathbf{F}$

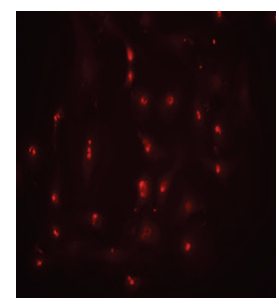

C

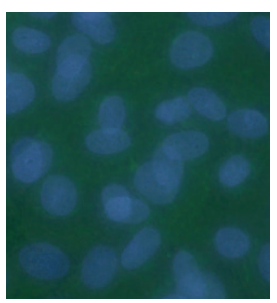

G

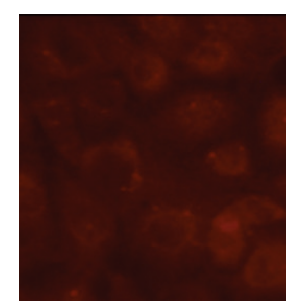

D

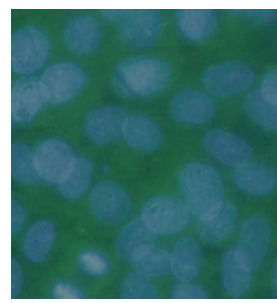

H

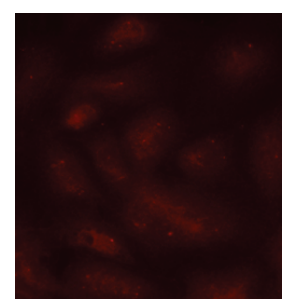

Fig. 4. Immunofluorescent staining of TLR-2, TLR-4, caspase-1 and IL-18 on 7-day IEC-18 cultures at a magnification of $40 x$. Images were taken in the center of the wells. TLR-2 (A, B) and TLR-4 (C, D) were stained green in cytoplasm. Nuclei visualized with DAPI (blue in C, D) showed even distribution of cells. IL-18 (E, F) and caspase-1 $(\mathbf{G}, \mathbf{H})$ were stained red in cytoplasm. L. casei LOCK0919 (L919) present $2 \mathrm{~h}$ in culture stimulated expression of TLR-2, TLR-4, IL-18 and caspase-1 (B, D, F, H) compared to controls (A, C, E, G). Staining procedure with primary and secondary antibodies as presented in Materials and Methods.

\section{A $\quad$ B}

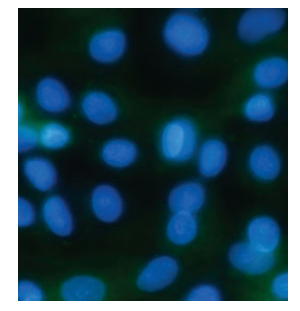

C

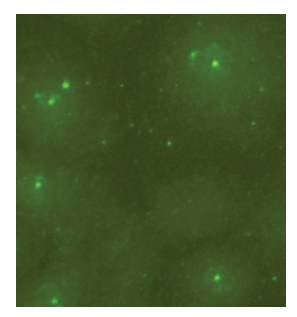

G

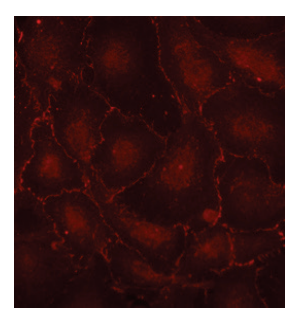

D

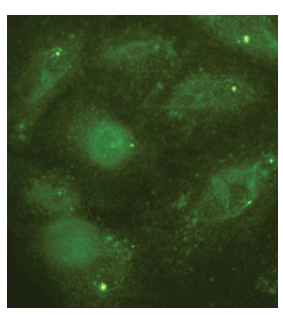

H

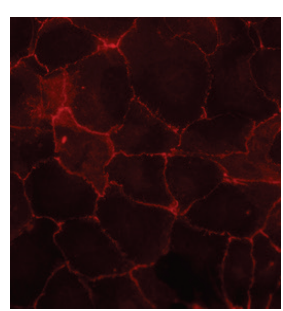

E

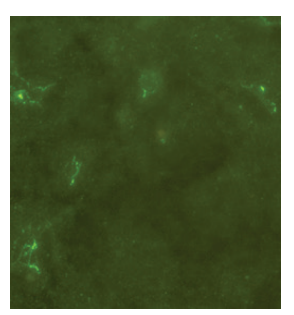

I

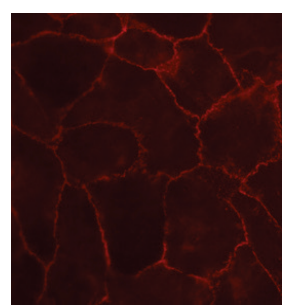

$\mathbf{F}$

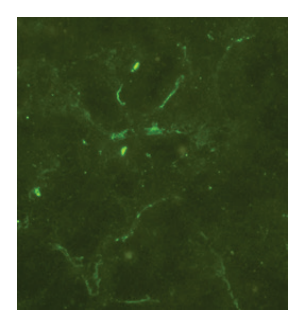

J

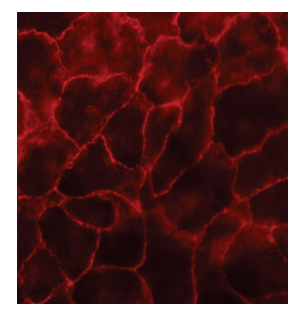

Fig. 5. Villin and $\beta$-catenin expression in control and in L. casei LOCK0919 (L919) treated IEC-18 culture evaluated by fluorescent microscopy; villin (green), $\quad \beta$-catenin (red). (A) IEC-18 5-day control culture, villin expressed near the nuclei (DAPI, blue). (B) In IEC-18 5-day culture on Matrigel villin expression was stimulated in cytoplasm. (C) Control culture on Day 3 and (E) control culture on Day 7 , villin evenly distributed in cytoplasm. L. casei LOCK0919 stimulated expression of villin in the cytoplasm of 3-day culture (D) and in 7-day culture (F) with villin expression appearing in membrane structures of some cells. (G) In 3-day control culture $\beta$-catenin is expressed mainly in cytoplasm, while under the effect of L. Casei LOCK0919 transfer to cell membrane is seen (H). In 7-day control culture most of $\beta$-catenin is expressed on cell membranes (I). Cultivation with L. casei LOCK0919 (J) increased $\beta$-catenin expression in the cytoplasm of some cells and intensified $\beta$-catenin association with membranes. 
Immunofluorescent localization of proteins TLR-2, TLR-4, caspase-1 and IL-18 on IEC-18 cells: exposure to L. casei LOCK0919

Immunofluorescent staining was performed on IEC-18 cells cultivated for 7 days on glass in the absence of ECM to get a better view of independent effect of bacteria. After IEC-18 cells were exposed to $L$. casei LOCK0919, an increase of immunofluorescence of TLR-2, TLR-4, caspase-1 and IL-18 proteins was more pronounced in the cytoplasm of IEC-18 cells in comparison with control cytoplasm without bacteria (Fig. 4).

L. casei LOCK0919 modulated villin and $\beta$-catenin expression in IEC-18 cells: immunofluorescence study

Villin is a tissue specific actin-binding protein expressed in microvilli in the brush borders of enterocytes. It participates in the assembly of the intestinal brush-border cytoskeleton and in the maintenance of brush-border architecture (Athman et al. 2002). Our results presented in Figure 5 clearly showed the stimulating effect of Matrigel on the expression of villin in the IEC-18 cells cultivated for 5 days (Fig. 5B). Villin is synthesized in small amount without Matrigel support (Fig. 5A). To eliminate the effect of ECM in studies with probiotic bacteria, the IEC-18 cells were cultivated on plates without Matrigel. On cultivation for 3 days (Fig. 5C) and 7 days (Fig. 5E) the expression of villin in control culture did not substantially differ from that at Day 5 in even distribution in the cytoplasm. Cultivation of IEC-18 cells with L. casei LOCK0919 strain stimulated villin expression on Day 3 to form spherical structures thicken with villin (Fig. 5D) compared to control (Fig. 5C); cultivation with L. casei LOCK0919 for 7 days stimulated villin to concentrate in narrow lines that may represent membrane structures of IEC-18 cells (Fig. 5F) compared to control (Fig. 5E).

$\beta$-catenin is associated with adherens junctions (AJs) where it functions as a component of the cadherin complex that controls cell-cell adhesion by linking cadherin to the actin cytoskeleton (Nelson and Nusse 2004). The rate of $\beta$-catenin expression and localization was increased in the course of differentiation from cytoplasm on Day 3 (Fig. 5G) into cell membrane on Day 7 (Fig. 5I). L. casei LOCK0919 stimulated transfer of $\beta$-catenin to cell membrane of less differentiated cells on Day 3 to cell membrane (Fig. $5 \mathrm{H}$ ) and intensified expression of $\beta$-catenin in cell membrane in more differentiated cells on Day 7 (Fig. 5J).

\section{Discussion}

This study was undertaken to examine whether the three probiotic Lactobacillus strains, known for anti-allergic response, can accelerate differentiation of non-transformed rat crypt-like small intestinal line IEC-18 and regulate its immune function including production of inflammatory cytokines. Nonmalignant IEC lines require for differentiation and return of cell polarization in vitro external basement membrane matrix or collagen gels supports to induce a spectrum of changes toward differentiation (Sanderson et al. 1996). Epithelial cells detect microbes through the Toll-like receptors as transmembrane signal transducing receptors. We showed that individual Lactobacillus strains are recognized differently by TLR-2 and TLR-4 of IEC-18 cells and that this interaction plays crucial role in acceleration of intestinal cell differentiation from undifferentiated towards a more differentiated state. In this study, L. rhamnosus LOCK0908 was not modifying TLR-2 and TLR-4 mRNA expression in IEC-18 cells. Similarly, there is no interaction of L. rhamnosus LOCK0908 strain with HEK293 cells transfected with either TLR-2 or TLR-4, likely due to masking bioactive components for binding by its high level of surface exopolysaccharides (Kozakova et al. 2016). In contrast, L. rhamnosus LOCK0900 contain polysaccharides that in isolated form modulate immune response of $L$. plantarum WCFS1 by enhancing production of IL-10 and IL-12p70 of dendritic cells (Gorska et al. 2014). L. rhamnosus LOCK0900 is recognized by TLR-2 inducing its mRNA expression after IEC detachment from ECM and, in addition, also by inducing internal cytosolic NOD2 receptor by up-regulating its transcription. Stimulation of NOD2 leads to the activation of transcription factor NF- $\mathrm{NB}$ (Martinon et al. 2004). L. rhamnosus LOCK0900 strain does not signal through TLR-4, consistent with HEK293/TLR-4 cell system (Kozakova et al. 2016).

L. casei LOCK0919 is recognized by both TLR-2 and TLR-4, as shown by up-regulation of their mRNA and increased immunostaining of their proteins in the cytoplasm. Similarly, L. paracasei NCC2461 acts through both TLR-2 and TLR-4 in HEK293 cell system (Schabussova et al. 2012). Our Western blot data show that the protein size of both TLR-2 and TLR-4 between 100-105 kDa after 7-day cultivation appeared to be partially glycosylated molecular forms with majority immunostaining in the cytoplasm of IEC-18 cells. Similarly, Ohnishi et al. (2003) designed 110 kDa TLR-4 
as partially glycosylated protein expressing TLR-4 without helper myeloid factor-2 (MD-2) on HEK293 cells. An even lesser glycosylated $97 \mathrm{kDa}$ TLR-4 protein (Neal et al. 2006) and $85 \mathrm{kDa}$ of TLR-2 and $92 \mathrm{kDa}$ of TLR-4 (Cario et al. 2000) indicated both TLR-2 and TLR-4 with majority staining in the cytoplasm of IEC-6 cells. According to Ohnishi et al. (2003) TLR-4 is able to undergo glycosylation at multiple positions, $110 \mathrm{kDa}$ being partially glycosylated and the $130 \mathrm{kDa}$ being the only one form expressed in a small portion on the cell surface. This specific glycosylation form of TLR-4 requires the presence of a helper myeloid factor-2 (MD-2) to function as a membrane receptor. Question arises by which mechanism bacterial translocation occurs across the intestinal barrier. It was shown that IEC can transfer bacteria into internalized TLR receptor vesicles or phagosomes upon the interaction of TLR with bacterial ligand (Neal et al. 2006, Sanderson and Walker 2007).

Recent tests demonstrate that L.casei LOCK0919 is a dominant strain colonizing mouse intestine due to high adherence to enterocytes originating from an unusual plasmid-localized pilus gene cluster (Aleksandrzak-Piekarczyk et al. 2015). This is highly similar to that of L. rhamnosus GG and different from those of L. rhamnosus LOCK0900 and L. rhamnosus LOCK0908 which do not encode such pilus gene cluster. The increased adhesion of L. casei LOCK0919 to enterocytes may enhance protection against pathogen adhesion. Our results indicate that in the course of differentiation of intestinal epithelial cells Lactobacillus strains can directly stimulate inflammatory activities of IEC-18 cells including production of inflammatory cytokines of IL-1 family, IL-1 $\beta$ and IL-18. These cytokines cause a variety of biological effects associated with infection and inflammation; experimental colitis in mice mimics human Crohn's disease (Hudcovic et al. 2009).

Cytokine IL-1 $\beta$ is closely related to IL-18; both possess similar three dimensional structure and their precursor forms are inactive and remain intracellularly located until cleaved by cysteine protease caspase-1. However, there is a specific difference between IL-18 and IL-1 $\beta$. Whereas IL-18 is constitutively expressed in epithelial cells of the entire gastrointestinal tract, gene expression of IL-1 $\beta$ in epithelial cells under normal conditions is absent (Dinarello et al. 2013) until stimulated by signals activating NF- $\mathrm{B}$. IL-18, its receptors IL-18R $\alpha$ and IL-18R $\beta$ and caspase- 1 are constitutively expressed in rat IEC-6 line derived from the whole small intestine (Kolinska et al. 2008). Here we showed further that when activated at the apical surface of IEC-18 cells by a mixture of L. casei LOCK0919, L. rhamnosus LOCK0900 and L. rhamnosus LOCK0908 the bacterially induced promotor sequence of IL-18 is induced, as proposed for lipopolysaccharide (LPS) by Foss et al. (2001).

Caspase-1 is constitutively activated within an inflammasome complex that includes intracellular receptors such as NLRP3, with structural similarity to NOD2 (Martinon et al. 2004) that activates conversion of pro-caspase-1 to active caspase-1 (Zaki et al. 2010). In IEC-18 extract we detected constitutive isoforms of active caspase-1, such as those reported before (Yamin et al. 1996, Feng et al. 2004) and stimulated by L. casei LOCK0919. Active caspase-1 is a prerequisite for obtaining biologically active mature and secreted IL-18 form. In this study, we showed that the polarized IEC-18 grown on collagen secreted IL-18 at both apical and basolateral poles depending on the state of differentiation. We speculate that in vivo at the basolateral side, IL-18 induces the production of chemokine IL- 8 and facilitates inflammatory signaling through stimulation of IL-18R $\beta$ (Kolinska et al. 2008) to induce IFN- $\gamma$ and exert inflammatory properties. Conversely, at the apical pole and in the intestinal cells the secreted IL-18 mediates proliferation, protection and preservation of the intestinal barrier and restores healing of damaged cells during infection (Siegmund 2010).

Our results also demonstrate that L. rhamnosus LOCK0900 increases transcription of caspase-1 and that both L. casei LOCK0919 and L. rhamnosus LOCK0900 strains stimulate gene expression of the signal adaptor molecule MyD88. MyD88 is a functional molecule to activate NF- $\mathrm{BB}$ critical for IL-18 and IL-1 $\beta$ signaling (Adachi et al. 1998) via their receptors, as well as TLRs/MyD88 dependent production of inflammatory cytokines in infections (Seki et al. 2002). While IL-18 transcript is expressed as differentiation marker of IEC-18 cells cultivated on extracellular matrix and stimulated by $L$. case $i$ LOCK0919, IL-1 $\beta$ is not present in non-transformed IEC-18 cells (Dinarello et al. 2013).

It is known that IL-1 $\beta$ gene expression is rapid as an early induced event of inflammation. Experimental procedure involving detachment of IEC-18 cells from extracellular matrix is considered as a stress stimulus for IL-1 $\beta$ transcript production until $1 \mathrm{~h}$ after detachment (Waterhouse and Stadnyk 1999). In addition to stimulation of IL-1 $\beta$, we observed increased transcription 
of TLR-2 and IL-8 in detached cells in the presence of L. rhamnosus LOCK0900 strain. Previously was shown that IEC-6 cells respond to detachment by producing mRNA and protein of cytokine IL-6 (Miller and McGee 2002). Furthermore, detachment directly activates NF- $\kappa B$ (Yan et al. 2005). We speculate that expressed TLR-2 mediates the signal from microbial components of L. rhamnosus LOCK0900 through MyD88 dependent pathway and stimulates transcription factor NF- $\kappa \mathrm{B}$ and IL-8 and IL-6 gene transcription. IL-6 gene expression may be also enhanced by IL-1 $\beta$ (McGee et al. 1993). $\mathrm{NF}-\kappa \mathrm{B}$ promotes expression of antiapoptotic and proapoptotic molecules (Yan et al. 2005). IL-1 $\beta$ protects IEC from apoptosis, which may protect integrity of epithelial monolayer (Waterhouse et al. 2001). L. rhamnosus LOCK0900 also stimulates gene expression of cytosolic bacterial recognition molecule NOD2 in detached IEC-18 cells. This coincided with NOD2 gene expression in mouse ileal crypts dependent on commensal flora; L. plantarum increasing NOD2 mRNA in wild mice vs. mRNA in germ-free mice (Petnicki-Ocwieja et al. 2009).

Cytoskeleton binding proteins villin and $\beta$-catenin were studied by immunofluorescence under the effect of L. casei LOCK0919 to evaluate the effect on differentiation of cellular morphology. This strain is known for strong adherence to enterocytes (Aleksandrzak-Piekarczyk et al. 2015) and modulatory effect of its polysaccharides on immune response to L. plantarum WCFS1 (Gorska et al. 2016). We demonstrated that villin in IEC-18 cells is dependent on cell differentiation in ECM fashion. However, villin was detected in IEC-18 cells grown on glass as in Sanderson et al. (1996) and Wang et al. (2003). We cultivated the cells on glass to get a better view of an independent effect of bacteria. L. casei LOCK0919 accelerates subcellular distribution of villin, its localization from the cytoplasm approaching the cell membrane of a number of cells. $\beta$-catenin expression and change in localization were increased during IEC-18 cell differentiation. Its transfer from cytoplasm to cell membrane was stimulated by L. casei LOCK0919. In normal development, $\beta$-catenin functions in cell adhesion, linking catherin to $\alpha$-catenin and binding this complex with the cytoskeleton (Harris and Peifer 2005). Free $\beta$-catenin plays a role in transcription via Wnt-canonical pathway regulating cell cycle, cell growth and proliferation. Inhibition of $\beta$-catenin signaling plays a key role in pathogenesis of necrotizing enterocolitis via impaired enterocyte proliferation (Sodhi et al. 2010).

In this study, we focused on the sequences of evens in the process of differentiation of intestinal epithelial cells as an active participant in the mucosal response to the commensal Lactobacillus strains that can directly activate immune and morphological functions of intestinal epithelial cells. We support the notion that newly made membrane proteins are delivered to the surface with different speed, TLRs vs. structural markers, and that degree of glycosylation is essential for surface expression. Different response of individual Lactobacillus strains to production of inflammatory cytokines points to tightly controlled specific induction of inflammatory cytokine IL-1 $\beta$ in detached IEC-18 cells by L. rhamnosus LOCK0900.

\section{Conflict of Interest}

There is no conflict of interest.

\section{Acknowledgements}

This study was supported by grants ME10017 and 7AMB16PL006 of the Ministry of Education, Youth and Sports of the Czech Republic.

\section{References}

ADACHI O, KAWAI T, TAKEDA K, MATSUMOTO M, TSUTSUI H, SAKAGAMI M, NAKANISHI K, AKIRA S: Targeted disruption of the MyD88 gene results in loss of IL-1- and IL-18-mediated function. Immunity 9: 143-150, 1998.

ALEKSANDRZAK-PIEKARCZYK T, KORYSZEWSKA-BAGINSKA A, BARDOWSKI J: Genome sequence of the probiotic strain Lactobacillus rhamnosus (formerly Lactobacillus casei) LOCK900. Genome Announc 1: e00640-13, 2013.

ALEKSANDRZAK-PIEKARCZYK T, KORYSZEWSKA-BAGINSKA A, GRYNBERG M, NOWAK A, CUKROWSKA B, KOZAKOVA H, BARDOWSKI J: Genomic and functional characterization of the unusual pLOCK 0919 plasmid harboring the spaCBA pili cluster in Lactobacillus casei LOCK 0919. Genome Biol Evol 8: 202-217, 2015. 
ATHMAN R, LOUVARD D, ROBINE S: The epithelial cell cytoskeleton and intracellular trafficking. III. How is villin involved in the actin cytoskeleton dynamics in intestinal cells? Am J Physiol Gastrointest Liver Physiol 283: G496-G502, 2002.

BARNICH N, AGUIRRE JE, REINECKER HC, XAVIER R, PODOLSKY DK: Membrane recruitment of NOD2 in intestinal epithelial cells is essential for nuclear factor-kappaB activation in muramyl dipeptide recognition. J Cell Biol 170: 21-26, 2005.

BLOBEL G, WALTER P, CHANG CN, GOLDMAN BM, ERICKSON AH, LINGAPPA VR: Translocation of proteins across membranes: the signal hypothesis and beyond. Symp Soc Exp Biol 33: 9-36, 1979.

CARIO E, ROSENBERG IM, BRANDWEIN SL, BECK PL, REINECKER HC, PODOLSKY DK: Lipopolysaccharide activates distinct signaling pathways in intestinal epithelial cell lines expressing Toll-like receptors. J Immunol 164: 966-972, 2000.

CUKROWSKA B, ROSIAK I, KLEWICKA E, MOTYL I, SCHWARZER M, LIBUDZISZ Z, KOZAKOVA H: Impact of heat-inactivated Lactobacillus casei and Lactobacillus paracasei strains on cytokine responses in whole blood cell cultures of children with atopic dermatitis. Folia Microbiol (Praha) 55: 277-280, 2010.

DINARELLO CA, NOVICK D, KIM S, KAPLANSKI G: Interleukin-18 and IL-18 binding protein. Front Immunol 4: 289-299, 2013.

FENG Q, LI P, LEUNG PC, AUERSPERG N: Caspase-1zeta, a new splice variant of the caspase-1 gene. Genomics 84: 587-591, 2004.

FOSS DL, ZILLIOX MJ, MURTAUGH MP: Bacterially induced activation of interleukin-18 in porcine intestinal mucosa. Vet Immunol Immunopathol 78: 263-277, 2001.

FUSUNYAN RD, NANTHAKUMAR NN, BALDEON ME, WALKER WA: Evidence for an innate immune response in the immature human intestine: toll-like receptors on fetal enterocytes. Pediatr Res 49: 589-593, 2001.

GARDELLA S, ANDREI C, COSTIGLIOLO S, POGGI A, ZOCCHI MR, RUBARTELLI A: Interleukin-18 synthesis and secretion by dendritic cells are modulated by interaction with antigen-specific T cells. J Leukoc Biol 66: 237-241, 1999.

GOLIAS J, HUMLOVA Z, HALADA P, HABOVA V, JANATKOVA I, TUCKOVA L: Identification of rice proteins recognized by the IgE antibodies of patients with food allergies. J Agric Food Chem 61: 8851-8860, 2013.

GORSKA S, SCHWARZER M, JACHYMEK W, SRUTKOVA D, BRZOZOWSKA E, KOZAKOVA H, GAMIAN A: Distinct immunomodulation of bone marrow-derived dendritic cell responses to Lactobacillus plantarum WCFS1 by two different polysaccharides isolated from Lactobacillus rhamnosus LOCK 0900. Appl Environ Microbiol 80: 6506-6516, 2014.

GORSKA S, HERMANOVA P, CIEKOT J, SCHWARZER M, SRUTKOVA D, BRZOZOWSKA E, KOZAKOVA H, GAMIAN A: Chemical characterization and immunomodulatory properties of polysaccharides isolated from probiotic Lactobacillus casei LOCK 0919. Glycobiology 26: 1014-1024, 2016.

HARRIS TJ, PEIFER M: Decisions, decisions: beta-catenin chooses between adhesion and transcription. Trends Cell Biol 15: 234-237, 2005.

HEATH JP: Epithelial cell migration in the intestine. Cell Biol Int 20: 139-146, 1996.

HUDCOVIC T, KOZÁKOVÁ H, KOLÍNSKÁ J, ŠTĚPÁNKOVÁ R, HRNČÍŘ T, TLASKALOVÁ-HOGENOVÁ H: Monocolonization with Bacteroides ovatus protects immunodeficient SCID mice from mortality in chronic intestinal inflammation caused by long-lasting dextran sodium sulfate treatment. Physiol Res 58: 101-110, 2009.

ISMAIL AS, HOOPER LV: Epithelial cells and their neighbors. IV. Bacterial contributions to intestinal epithelial barrier integrity. Am J Physiol Gastrointest Liver Physiol 289: G779-G784, 2005.

JALAL F, JUMARIE C, BAWAB W, CORBEIL D, MALO C, BERTELOOT A, CRINE P: Polarized distribution of neutral endopeptidase 24.11 at the cell surface of cultured human intestinal epithelial Caco-2 cells. Biochem J 288: 945-951, 1992.

KEDINGER M: What triggers intestinal cells to move or stay and to proliferate or differentiate? Gastroenterology 107 : 885-888, 1994. 
KOLINSKA J, LISA V, CLARK JA, KOZAKOVA H, ZAKOSTELECKA M, KHAILOVA L, SINKORA M, KITANOVICOVA A, DVORAK B: Constitutive expression of IL-18 and IL-18R in differentiated IEC-6 cells: effect of TNF-alpha and IFN-gamma treatment. J Interferon Cytokine Res 28: 287-296, 2008.

KORYSZEWSKA-BAGINSKA A, ALEKSANDRZAK-PIEKARCZYK T, BARDOWSKI J: Complete genome sequence of the probiotic strain Lactobacillus casei (formerly Lactobacillus paracasei) LOCK919. Genome Announc 1: e00758-13, 2013.

KORYSZEWSKA-BAGINSKA A, BARDOWSKI J, ALEKSANDRZAK-PIEKARCZYK T: Genome sequence of the probiotic strain Lactobacillus rhamnosus (formerly Lactobacillus casei) LOCK908. Genome Announc 2: e00120-14, 2014.

KOZAKOVA H, SCHWARZER M, TUCKOVA L, SRUTKOVA D, CZARNOWSKA E, ROSIAK I, HUDCOVIC T, SCHABUSSOVA I, HERMANOVA P, ZAKOSTELSKA Z, ALEKSANDRZAK-PIEKARCZYK T, KORYSZEWSKA-BAGINSKA A, TLASKALOVA-HOGENOVA H, CUKROWSKA B: Colonization of germ-free mice with a mixture of three lactobacillus strains enhances the integrity of gut mucosa and ameliorates allergic sensitization. Cell Mol Immunol 13: 251-262, 2016.

MARTINON F, AGOSTINI L, MEYLAN E, TSCHOPP J: Identification of bacterial muramyl dipeptide as activator of the NALP3/cryopyrin inflammasome. Curr Biol 14: 1929-1934, 2004.

MCGEE DW, BEAGLEY KW, AICHER WK, MCGHEE JR: Transforming growth factor-beta and IL-1 beta act in synergy to enhance IL-6 secretion by the intestinal epithelial cell line, IEC-6. J Immunol 151: 970-978, 1993.

MICHELSEN KS, ARDITI M: Toll-like receptors and innate immunity in gut homeostasis and pathology. Curr Opin Hematol 14: 48-54, 2007.

MILLER TL, MCGEE DW: Epithelial cells respond to proteolytic and non-proteolytic detachment by enhancing interleukin-6 responses. Immunology 105: 101-110, 2002.

NEAL MD, LEAPHART C, LEVY R, PRINCE J, BILLIAR TR, WATKINS S, LI J, CETIN S, FORD H, SCHREIBER A, HACKAM DJ: Enterocyte TLR4 mediates phagocytosis and translocation of bacteria across the intestinal barrier. J Immunol 176: 3070-3079, 2006.

NELSON WJ, NUSSE R: Convergence of Wnt, beta-catenin, and cadherin pathways. Science 303: 1483-1487, 2004.

OHNISHI T, MUROI M, TANAMOTO K: MD-2 is necessary for the toll-like receptor 4 protein to undergo glycosylation essential for its translocation to the cell surface. Clin Diagn Lab Immunol 10: 405-410, 2003.

PETNICKI-OCWIEJA T, HRNCIR T, LIU YJ, BISWAS A, HUDCOVIC T, TLASKALOVA-HOGENOVA H, KOBAYASHI KS: Nod2 is required for the regulation of commensal microbiota in the intestine. Proc Natl Acad Sci U S A 106: 15813-15818, 2009.

RUBARTELLI A, COZZOLINO F, TALIO M, SITIA R: A novel secretory pathway for interleukin-1 beta, a protein lacking a signal sequence. EMBO J 9: 1503-1510, 1990.

SANDERSON IR, WALKER WA: TLRs in the Gut I. The role of TLRs/Nods in intestinal development and homeostasis. Am J Physiol Gastrointest Liver Physiol 292: G6-G10, 2007.

SANDERSON IR, EZZELL RM, KEDINGER M, ERLANGER M, XU ZX, PRINGAULT E, LEON-ROBINE S, LOUVARD D, WALKER WA: Human fetal enterocytes in vitro: modulation of the phenotype by extracellular matrix. Proc Natl Acad Sci U S A 93: 7717-7722, 1996.

SCHABUSSOVA I, HUFNAGL K, TANG ML, HOFLEHNER E, WAGNER A, LOUPAL G, NUTTEN S, ZUERCHER A, MERCENIER A, WIEDERMANN U: Perinatal maternal administration of Lactobacillus paracasei NCC 2461 prevents allergic inflammation in a mouse model of birch pollen allergy. PLoS One 7: e40271, 2012.

SEKI E, TSUTSUI H, TSUJI NM, HAYASHI N, ADACHI K, NAKANO H, FUTATSUGI-YUMIKURA S, TAKEUCHI O, HOSHINO K, AKIRA S, FUJIMOTO J, NAKANISHI K: Critical roles of myeloid differentiation factor 88-dependent proinflammatory cytokine release in early phase clearance of Listeria monocytogenes in mice. J Immunol 169: 3863-3868, 2002.

SIEGMUND B: Interleukin-18 in intestinal inflammation: friend and foe? Immunity 32: 300-302, 2010.

SODHI CP, SHI XH, RICHARDSON WM, GRANT ZS, SHAPIRO RA, PRINDLE T JR, BRANCA M, RUSSO A, GRIBAR SC, MA C, HACKAM DJ: Toll-like receptor-4 inhibits enterocyte proliferation via impaired betacatenin signaling in necrotizing enterocolitis. Gastroenterology 138: 185-196, 2010. 
STADNYK AW, JOSEPH RR, BLAKE KM: Regulation of cytokine expression in intestinal epithelial cells. Mod Asp Immunol 2: 73-77, 2001.

VALLEE S, LAFOREST S, FOUCHIER F, MONTERO MP, PENEL C, CHAMPION S: Cytokine-induced upregulation of NF-kappaB, IL-8, and ICAM-1 is dependent on colonic cell polarity: implication for PKCdelta. Exp Cell Res 297: 165-185, 2004.

WANG Z, CHEN WW, LI RL, WEN B, SUN JB: Effect of gastrin on differentiation of rat intestinal epithelial cells in vitro. World J Gastroenterol 9: 1786-1790, 2003.

WATERHOUSE CC, STADNYK AW: Rapid expression of IL-1beta by intestinal epithelial cells in vitro. Cell Immunol 193: 1-8, 1999.

WATERHOUSE CC, JOSEPH RR, STADNYK AW: Endogenous IL-1 and type II IL-1 receptor expression modulate anoikis in intestinal epithelial cells. Exp Cell Res 269: 109-116, 2001.

YAMIN TT, AYALA JM, MILLER DK: Activation of the native 45-kDa precursor form of interleukin-1-converting enzyme. J Biol Chem 271: 13273-13282, 1996.

YAN SR, JOSEPH RR, ROSEN K, REGINATO MJ, JACKSON A, ALLAIRE N, BRUGGE JS, JOBIN C, STADNYK AW: Activation of NF-kappaB following detachment delays apoptosis in intestinal epithelial cells. Oncogene 24: 6482-6491, 2005.

ZAKI MH, BOYD KL, VOGEL P, KASTAN MB, LAMKANFI M, KANNEGANTI TD: The NLRP3 inflammasome protects against loss of epithelial integrity and mortality during experimental colitis. Immunity 32: 379-391, 2010. 